\title{
Inversion dynamics in some population of an emerging vector of malaria Anopheles (Celia) subpictus Grassi (Diptera: Culicidae)
}

\section{S. Chaudhry, T. K aura*, Savita and R. K umar}

Mosquito Cytogenetics Unit, Department of Zoology, Panjab University, Chandigarh-160014, INDIA

*Corresponding author. E-mail: tarunakaura@yahoo.co.in

Received: N ovember 2, 2012; Revised received: February 2, 2013; Accepted: February 28, 2013

\begin{abstract}
The present paper deals with the polytene chromosome inversion polymorphism based genomic characterization of Anopheles subpictus Grassi (Culicidae: Diptera) which has attained the status of an emerging vector of malaria in Srilanka, West Bengal and some coastal parts of India. The inversion data of the present population from Hoshairpur, Punjab (pop.A), India has also been compared with five other populations of this species worked out earlier in this laboratory so as to have a comprehensive assessment of inversion dynamics in this taxon. From the percentage frequency of inversions it was also evident that both rural and urban populations of An. subpictus had nearly similar inversion frequencies. In addition to these observations, it was interesting to note that irrespective of the number of individuals sacrificed, cells studied and the number of aberrations encountered from each population, inversions always constituted $50 \%$ of the total mutational index. On the basis of the present comparative data of inversion polymorphism, it is logical to suggest that, similar to "meiotic drive" and "molecular drive" there is also a type of "inversion drive" which constantly changes population genomics to augment competitive fitness of the species. Our recent studies on the $r$ DNA ITS2 sequence variations also suggest this contension.
\end{abstract}

Keywords: Anopheles subpictus populations, Genomic, Inversions, Polytene chromosome

\section{INTRODUCTION}

Prior to the advent of molecular systematics the area of comparative cytogenetics of mosquitoes involved the comparison of the diploid karyotypes of the gonial metaphase and the banding pattern of the polytene chromosomes of different species of the genus Anopheles. As a result of these studies the occurrence of chromosomal polymorphism in the form of inversions and translocations proved quite useful in understanding the phylogenetic relationships, karyosystematics and speciation in the family Culicidae (Munstermann, 1995; Toure et al., 1998; Chaudhry, 1999; Subbarao et al ., 2000; Chaudhry, 2003; Chillar and Chaudhry, 2004). The data generated so far has revealed that most of the epidemiologically important species exist in the form of a complex of two or more sibling species with subspecific variants or biological species. In fact, the concept of species complexes first discovered in An. maculipennis and An. gambiae was the outcome of comparative cytogenetics involving species-specific polytene chromosome banding pattern (Coluzzi and Kitzmiller, 1975; Kitzmiller, 1976; Steiner et al., 1988; Subbarao et al., 1988; Green et al., 1992; Subbarao, 1996; Chaudhry, 1999; Beebe et al., 2000; Ramirez and Dessen, 2000; Chaudhry, 2003). In fact, the cytogenetic recognition of genotypic variations in some of the major vectors of malaria have actually provided some valuable information about the genetic basis of vectorial capacity and insecticide resistance. Inspite of the fact that cytogenetic investigations have graduated from chromosome analysis to PCR based DNA diagnostics yet polytene chromosome based genomic analysis is fundamental to molecular genomics as the use of species- specific banding pattern is a first important step in the molecular identification of sibling species in the family Culicidae. In relevance to this, the present paper deals with the polytene chromosome inversion polymorphism based genomic characterization of Anopheles subpictus Grassi (Culicidae: Diptera) which has attained the status of an emerging vector of malaria in Sri Lanka, West Bengal and some coastal parts of India (Panicker et al., 1981; Amersinghe et al., 1992; Abhayawardana, 1996 a b; Sahu, 1998; Chatterjee and Chandra, 2000, Chaudhry et al., 2005). Recently, Thenmozhi et al. (2006) have also detected its role as a vector of japanese encephalitis virus (JEV) in Cuddalore distrct, Tamil Nadu, India. The inversion data of the present population from Hoshairpur, Punjab (pop.A), India has also been compared with five other populations of this species worked out earlier in this laboratory so as to have a comprehensive assessment of inversion dynamics in this taxon.

\section{MATERIALS AND METHODS}

Anopheles subpictus is one of commonest species in the entire Indian subcontinent where its breeding is 
associated with clear rain water pools, water in hoof marks and leakage along irrigation channels (Rao, 1984). For the present purpose of research adults and larvae were collected from a village Khani near Hoshiarpur, Punjab (Latitude: $31^{\circ} 32^{\prime} \mathrm{N}$; Longitude: $75^{\circ} 57^{\prime} \mathrm{E}$ ) $136 \mathrm{kms}$ Northwest of Chandigarh (Latitude: $30^{\circ} 42^{\prime} \mathrm{N}$; Longitude: $76^{\circ}$ $\left.54^{\prime} \mathrm{E}\right)$ (Table 1). The fourth instar larvae were immediately sacrificed for obtaining the salivary glands while the younger stages were reared in the laboratory till they reached fourth instar stages. Alternatively, the field collected specimens were identified by following the keys of Wattal and Kalra (1967) and the species-specific banding pattern of the polytene $\mathrm{X}$ - chromosome (Chaudhry, 1986; Chaudhry and Rani, 1988; Chaudhry et al., 2005). The gravid females were held in test tubes in small numbers where they were allowed to lay eggs on a strip of wet filter paper. The eggs procured in this way were allowed to hatch in water filled rearing bowls where the larvae were fed on finely powdered and sieved mixture of dog buiscuits and yeast tablets (Singh et al. 1975, Clements 1992). The temporary squash preparations of polytene chromosomes were made by following the modified protocol of French et al. (1962) and Chaudhry et al. (2005). The desired quality of preparations were immediately examined under Nikon phase contrast microscope and photographed on a $35 \mathrm{~mm}$ black and white nova silver plus film of 200 ASA.

\section{RESULTS AND DISCUSSION}

Like all the species of the genus Anopheles, the diploid karyotype from the gonial metaphase of Anopheles subpictus consists of three pairs of unequal chromosomes ( $2 \mathrm{~N}=6, \mathrm{~B}$ and XY, @ and XX) represented by three polytene chromosomes of dimensions typical of the species belonging to subgenus Cellia. For the purpose of identifying the zones/ subzones invoved in the structural alterations, the polytene chromosme map produced by Chaudhry et al. (2005) was taken as a reference standard. Accordingly, the X-chromosome and the right and left arms of autosomes 2 and 3 (2R, 2L, 3R, $3 \mathrm{~L}$ ) were identified from the shape and banding pattern of the free and centromeric ends together with prominent series of bands and puffs along the length of each element (Chaudhry and Chaudhry, 1981). Nearby 200 larvae were sacrificed for studying the incidence of various different

Table 1. Sources and references of An. subpictus populations.

\begin{tabular}{|c|c|c|c|}
\hline S. No. & L ocality & Population & References \\
\hline 1 & P.U. Campus & Pop.A & Kaur, 1999 \\
\hline 2 & Khudda Lahora (Chd.) & Pop.B & Simarjot, 1995 \\
\hline 3 & Burail (Chd.) & Pop.C & Kumari, 1993 \\
\hline 4 & Nadasahib (HR) & Pop.D & Rani, 1984 \\
\hline 5 & Hoshiar pur (PB) & Pop.E & Savita, 2006 \\
\hline 6 & Sonipat (HR) & Pop.F & Chillar, 2001 \\
\hline
\end{tabular}

types of structural alterations. Accordingly, there were a total of 27 different types of structural aberrations out of which 12 were inversions, 8 instances of ectopically associated bands of the same or different chromosomes, 3 cases of insertional translocations, 2 asynaptic regions and 2 telomeric fusions. These types of structural changes are in conformity with the results obtained earlier by various workers about the incidence of chromosomal polymorphism in a number of species from the Oriental region (Chaudhry and Soni, 1987; Chaudhry, 1999; Suguna et al., 1994; Subbarao et al., 1994, 1999; Chillar and Chaudhry, 2004; Chaudhry et al., 2005). As a consequence of the emergence of An. subpictus as a potential vector of human malaria and JEV, it became mandatory to study the pattern of chromosomal from different regions. The logic behind such an exercise lies in the fact that certain inversions have been found to be responsible for influencing the vectorial capacity and insecticide resistance of a species. For this, the chromosomal polymorphism in the present population was compared with five other populations of this species worked out earlier in this laboratory (Tables 2,3,4). The total number of different types of aberrations reported by various workers along with the zones/subzones of chromosomes involved, percentage frequency of inversions and percentage frequency of inversions in individual chromosomal arm was taken into consideration for the final assessment of inversion dynamics as inversions predominate all the other types of structural alterations. The maximum number of paracentric heterozygous inversions in the autosomes were concentrated in $2 \mathrm{~L}$ zones 22 to 25 and $3 \mathrm{R}$ zones 30 to 32 as these regions seem to be more prone to this two break chromosomal rearrangements. From the percentage frequency of inversions it was also evident that both urban and rural populations of An. subpictus had nearly similar inversion frequencies. In other words, the host preference for a blood meal i.e. anthrophilic and zoophilic tendencies had no marked effect in modifying the genomic qualities of the species. In addition to these observations, it was interesting to note that irrespective of the number of individuals sacrificed, cells studied and the number of aberrations encountered from a population, inversions always constituted $50 \%$ of the total mutational load. The inversions in a large number of populations of this species 


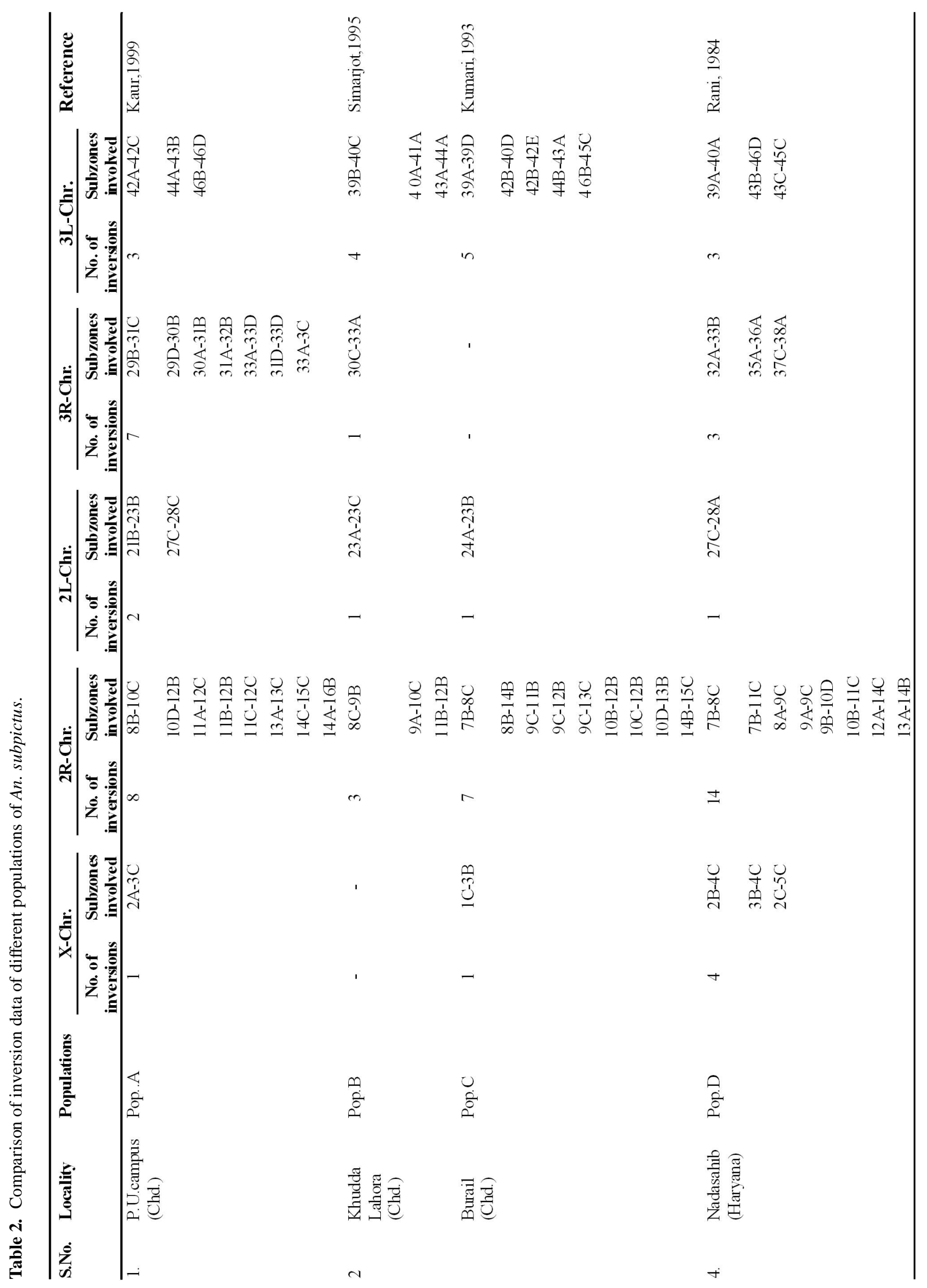




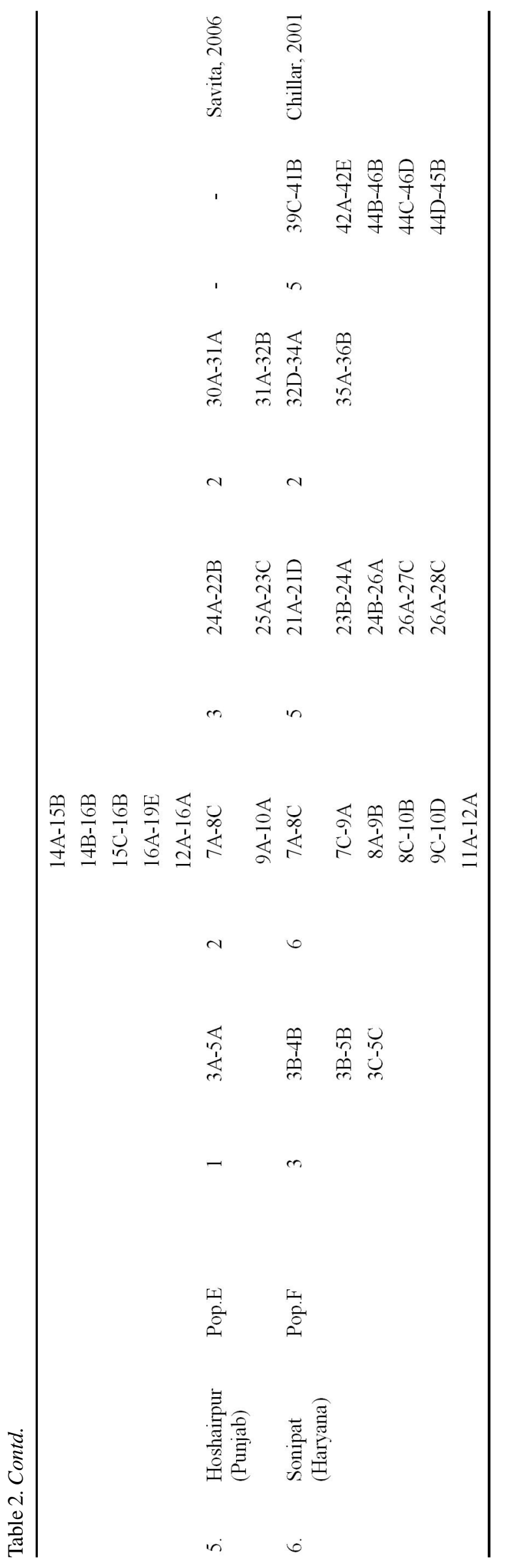

studies carried out so far have revealed that except for one fixed inversion in the $\mathrm{X}$ - chromosome which differentiates the four sibling species of An. subpictus complex, the rest fall in the category of floating inversions (Suguna, 1982; Reuben and Suguna, 1983; Suguna et al., 1994; Subbarao, 1996; Subbarao and Sharma, 1997; Chaudhry and Soni, 2000). For example, Subbarao (1998) and Subbarao and Sharma (1997) found the Oriental Anopheles subpictus to be a complex of a four reproductively isolated sibling species $\mathrm{A}, \mathrm{B}, \mathrm{C}$ and $\mathrm{D}$ recognized as four inversion genotypes viz: A- $\mathrm{X}^{\mathrm{a}+\mathrm{b}}$, B$\mathrm{X}^{\mathrm{ab}}, \mathrm{C}-\mathrm{X}^{\mathrm{a}+\mathrm{b}}$ and D- $\mathrm{X}^{\mathrm{ab}}$. It can therefore be advocated that fixed inversions act as sources of evolution and speciation while floating inversions have an adaptive significance for a number of environmental factors to which the species are generally exposed but well adapted. On the basis of the present comparative data of inversion polymorphism, it is logical to suggest that similar to "meiotic drive" and "molecular drive" there is a type of "inversion drive" which constantly changes population genomics. In other words, natural selection operates through genotypic novelties with a close relationship between differentiation of species and their genomes through favourable mutations to promote there genetic fitness. In case of An. subpictus the term emerging vector is a fit case for extensive studies on genome sequence variations. In light of these implications of DNA diagnostics of epidemiologically important species, recently Kaura et al. (2009) extended these studies further to analyse the PCR based sequence polymorphism in the rDNAITS 2 of this species from areas around Chandigarh. They compared the incidence of sequence variations in as many as five populations comprising the Indian component of the taxon with inland and coastal populations of Srilanka (Abhyawardana et al., 1996 a, b). Their results included the PCR amplified product size, AT: GC content, insertion, deletion (indels) and transition transversion (ts/tv) frequencies, interspersed repeats and phylogram of genetic kinship. Recently, Chillar (2008) covered three different parameters of species discrimination by studying the polytene chromosome characterstics, morphometric analysis of head region (maxillary palps, palpomeres, proboscis, antenna), wing venation and sequence details of ITS2 and COII gene. According to him, Anopheles subpictus is represented by only two sibling species, A (inland) and B (coastal) as enough evidence could not be generated to support the earlier view for the presence of A, B, C and D. In relevance to these observartions, it is pertinent to add that the present results belong to species B whereas sufficient scope still exists to carry out sequence analysis of favourable regions of nuclear and mitochondrial DNA using specific primers and RFLP markers (Chaudhry and Kohli, 2007; Kohli and Chaudhry, 2007; Kaura et al., 2009). 
Table 3. Percentage frequency of inversions in different populations of An. subpictus.

\begin{tabular}{llccccccc}
\hline S. No. & Locality & Population & X-Chr & 2R-Chr & 2L -Chr & 3R-Chr & 3L-Chr & R eference \\
\hline 1. & P.U. Campus & Pop.A & 0.00 & 29.40 & 11.76 & 35.20 & 23.50 & Kaur, 1999 \\
& (Chd.) & & +7.60 & +30.70 & +15.30 & +30.70 & +15.30 & \\
2. & Khudda Lahora & Pop.B & 0.00 & 22.23 & 29.62 & 14.81 & 33.34 & Simarjot, \\
& (Chd.) & & & +37.50 & +12.50 & +12.50 & +37.50 & 1995 \\
3. & Burail (Chd.) & Pop.C & 6.25 & 56.25 & 6.25 & 0.00 & 31.25 & Kumari, 1993 \\
4. & NadaSahib (Hr.) & Pop.D & 15.38 & 61.53 & 76.15 & 76.15 & 76.15 & Rani, 1984 \\
& & & +15.00 & +65.0 & & & & \\
5. & Hoshiarpur (Pb.) & Pop.E & 25.00 & 16.67 & 25.00 & 25.00 & 0.00 & Savita, 2006 \\
6. & Sonipat (Hr.) & Pop.F & 12.50 & 37.50 & 20.83 & 8.33 & 20.83 & Chillar, 2001 \\
\hline
\end{tabular}

Table 4. Comparison of percentage frequency of inversions in individual chromosomal arm in different populations of An. subpictus.

\begin{tabular}{llccccc}
\hline S. No. & Place & Populations & $\begin{array}{c}\text { Total no. of } \\
\text { aberrations }\end{array}$ & $\begin{array}{c}\text { Total no. } \\
\text { of } \\
\text { inver sions }\end{array}$ & $\begin{array}{c}\% \text { of } \\
\text { inversions }\end{array}$ & Refer ence \\
\hline 1. & P.U. campus (Chd.) & Pop.A & $25+28$ & $17+13$ & 68.00 & Kaur, 1999 \\
& & & & & +53.33 & \\
2. & Khudda Lahora (Chd.) & Pop.B & $45+15$ & $27+8$ & 68.00 & Simarjot, 1995 \\
& & & & +53.33 & \\
3. & Burail (Chd.) & Pop.C & 25 & 16 & 64.00 & Kumari, 1993 \\
4. & Nadasahib (Hr.) & Pop.D & $28+32$ & $14+20$ & 50.00 & Rani, 1984 \\
& & & & & +62.50 & \\
5. & Hoshiarpur (Pb.) & Pop.E & 27 & 12 & 44.44 & Savita, 2006 \\
6. & Sonipat (Hr.) & Pop.F & 40 & 24 & 60.00 & Chillar, 2001 \\
\hline
\end{tabular}

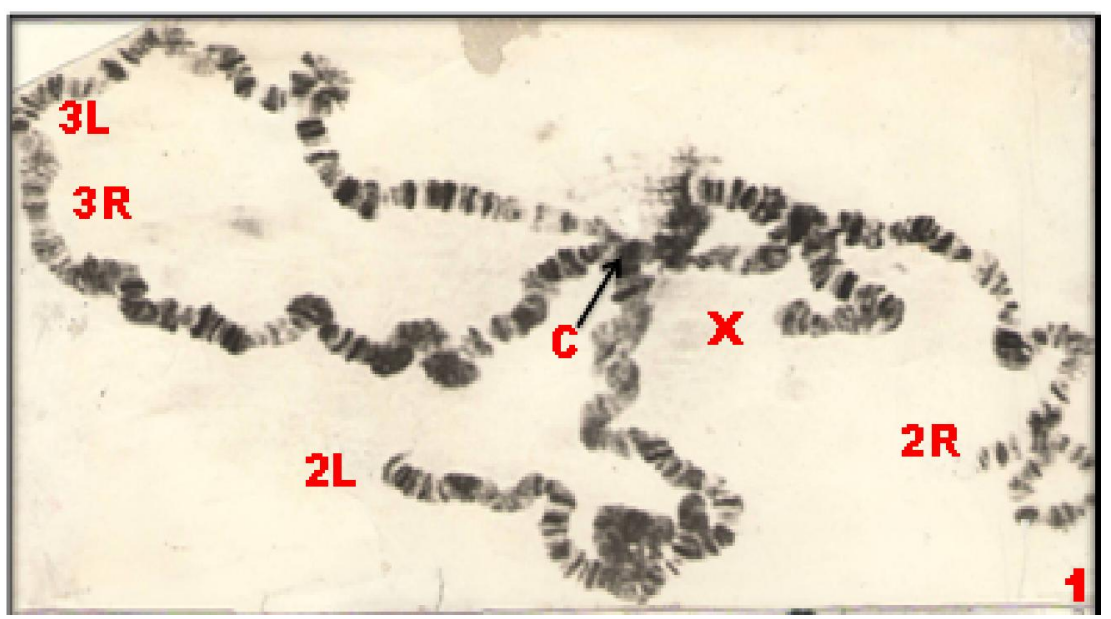

Fig.1. Complete set of three polytene chromosomes of A nopheles subpictus (X-chromosome and right and left arms of chromosomes 2 and 3-2R, 2L, 3R, 3L). C-chromocentre.

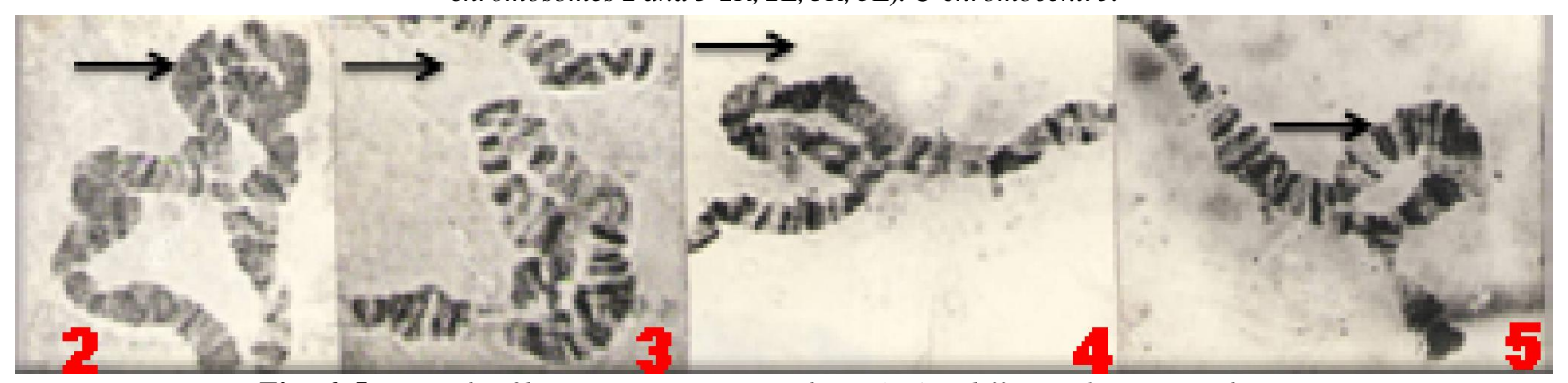

Figs. 2-5. Example of heter ozygous inversion loops $\rightarrow$ in differ ent chromosomal arms. 


\section{ACKNOWLEDGEMENTS}

The authors are thankful to the University Grants Commission, New Delhi for providing the necessary facilities under its Special Assistance Programme $\{$ F.54-8/2001 (SAP-II) $\}$ to the Department of Zoology, Panjab University, Chandigarh.

\section{REFERENCES}

Abhyawardana, T.A., Dilrukshi, R.K. and Wijesuriya, S.R. (1996a). Cytotaxonomical examination for cryptic species in the taxon Anopheles culicifacies Giles in Srilanka. Indian J ournal of Malariology, 33(2): 74-80.

Abhyawardana, T.A., Dilrukshi, R.K. and Wijesuriya, S.R. (1996b). Anopheles subpictus complex: distribution of cryptic species in Srilanka. Indian J ournal of M alariology. 33(2): 53-60.

Amerasinghe, P.H., Amerasinghe, F.P., Wirtz, R.A., Indrajith, N.G., Somapala, W., Pereira, L.R. and Rathnayake, A.M. (1992). Malaria transmission by Anopheles subpictus (Diptera: Culicidae) in a new irrigation project in Sri Lanka. J ournal of M edical E ntomology, 29(4): 577-581.

Beebe, N.W., Cooper, R.D., Morrison, D.A. and Ellis, J.T (2000). A phylogenetic study of the Anopheles punctulatus group of malaria vectors comparing rDNA sequence alignments derived from the mitochondrial and nuclear small ribosomal subunits. M olecular Phylogenetic Evolution, 17 (3): 430-436.

Chatterje, S. and Chandra, G (2000). Role of Anopheles subpictus as a primary vector of malaria in an area in India. Japan J ournal of Tropical M edicine H ygiene, 28(3): 177-181.

Chaudhry, S. (1986). Cytogenetics of two high altitude species of mosquitoes from India. Procceeding International Conference on Tropical Entomology Nairobi Kenya. 59-60.

Chaudhry, S. (1999). A review of polytene chromosome dynamics in Genus Anopheles (Diptera: Culicidae). In: R.C. Sobti and J.S. Yadav (eds.) Some aspects on the Insight of insect biology (pp 205-236), New Delhi: Tausco Book Distributors.

Chaudhry, S. (2003). Chromosomal evidence of sibling species in Anopheles (Anopheles) lindesayi Giles (Culicidae: Diptera). J ournal of C ytology and. G enetics, 4(NS): 115-120.

Chaudhry, S. and Chaudhry, A. (1981). Insertional linkage between salivary gland chromosomes $\mathrm{X}$ and $2 \mathrm{~L}$ of Anopheles stephensi (Diptera: Culicidae). Microbios Letters, 18: 77-80.

Chaudhry, S. and Kohli, R. (2007). Sequence analysis of mitochondrial $16 \mathrm{~S}$ ribosomal RNA gene fragment in two populations of Culex quinquefasciatus Say (Culicidae: Diptera). National Academy Science Letters, 30 (1 and 2): 55-60.

Chaudhry, S. and Rani, S. (1988). Sex chromosome in mosquitoes- III. A comparative study of the X-chromosome in some anopheline species of India (Culicidae: Diptera). In: O.P. Mittal (Eds.) Chromosome Dynamics, Panjab University.pp 153-158

Chaudhry, S., Neetu, Gupta, S. and Chhilar, J.S. (2005). Salivary polytene chromosome mapping of Anopheles (Cellia) subpi ctus Grassi (Culicidae: Diptera). Genome, 48 : 241-246.
Chaudhry, S. and Soni, K.G. (1987). Salivary polytene chromosomes of Anopheles splendidus and its cytogenetic relationship with A nophel es stephensi (Diptera: Culicidae). Res. Bull (Science) Part III-IV, Panjab Univ., Chandigarh, India. 38: 90-106.

Chaudhry, S. and Soni, K.G. (2000). Salivary X-chromosome in two allopatric populations of Anopheles subpictus Grassi from India. In Advances in medical zoology, D.S. Sidhu, J. Singh and D. Singh, Proceedings of the 5th International symposium on vectors and vector borne diseases Publications Bureau, Punjabi University, Patiala, India. pp 109-111.

Chillar, J.S. and Chaudhry, S. (2004). Polytene chromosome polymorphism in a semiurban population of a malaria vector Anopheles stephensi (Culicidae: Diptera). Proc. Zol. Soc. Calcutta. 57(1): 5-11.

Chillar, J.S. (2001). Cytogenetic investigations on salivary polytene chromosomes of two vector species of genus Anopheles (Diptera: Culicidae). M.Sc dissertation Panjab University, Chandigarh.

Chillar, J.S. (2008). Molecular characterization of mosquito genome. A study on emerging malaria vector Anopheles subpi ctus complex (Culicidae: Diptera).Ph.D Thesis Panjab University Chandigarh, India.

Clements, A.N. (1992). The Biology of Mosquitoes. (1) Chapman and Hill. London, U.K.

Coluzzi, M. and Kitzmiller, J.B. (1975). Anopheline mosquitoes. In Handbook of Genetics, R. C. King, Plenum Publishing Corporation, New York. pp 285-309.

French, W.L., Baker, R.H. and Kitzmiller, J.B. (1962). Preparation of mosquito chromosomes. M osquito News. 22: 337-383.

Green, C.A., Munstermann, L.E., Tan, S.G., Panyim, S. and Baimai, V. (1992). Population genetic evidence for species A, B, C and D of the Anopheles dirus complex in Thailand and enzyme electromorphs for their identification. M edical Veternary Entomology, 6: 29-36.

Kaur, B. (1999). Intraspecific genetic divergence in Anopheles (C ellia) subpictus Grassi (Culicidae: Diptera). M.Sc. Dissertation, Department of Zoology, Panjab University Chandiagrh.

Kaura, T., Sharma, M., Chaudhry, S. and Chaudhry, A. (2009). Sequence polymorphism in intron ITS2 of A nopheles (C ellia) subpictus Grassi (Diptera: Culicidae). Caryologia. 63(2): 124-133.

Kitzmiller, J.B. (1976). Genetics, cytogenetics and evolution of mosquitoes. In: Advances in Genetics (New York Academic Press. Inc.). 18: 315-433.

Kohli, R. and Chaudhry, S. (2007). Sequence analysis of mitochondrial $16 \mathrm{~S}$ ribosomal RNA gene fragment in the two populations of Armigeres (Armigeres) subalbatus (Culcidae: Diptera). Cytologia, 72(1): 83-88.

Kumari, V. (1993). Comparative Cytogenetic investigations on Anopheles subpictus Grassi (Culicidae: Diptera). M.Sc. Dissertation, Department of Zoology, Panjab University, Chnadigarh.

Munstermann, L.E. (1995). Mosquito systematics: Current status, new trends, associated complications. J ournal of Vector E cology, 20: 129-138.

Panicker, K.N., Geethabai, M., Bheema, Rao, U.S., Viswam, 
K. and Suryanaryana, M.V. (1981). Anopheles subpictus a vector of malaria in coastal villages of South east India. Current Science, 50: 694-695.

Rani, S. (1984). Studies on the salivary gland chromosomes of some Anopheline mosquitoes (Culicidae: Diptera). Ph.D thesis Panjab University, Chandigarh.

Rao, T.R. (1984). The Anophelines of India. Malaria Research Centre (ICMR), Delhi India.

Raimrez, C.C. and Dessen, E.M. (2000). Chromosome differentiated populations of A nopheles cruzii: evidence for a third sibling species. G enetica, 108: 73-80.

Reuben, R. and Suguna, S.U. (1983). Morphological differences between sibling species of the taxon Anopheles subpictus Grassi in India, with notes on relationship with known forms. M osquito News, 15(2): 117-126.

Sahu, S.S. (1998). Comparative susceptibility of Anopheles subpictus from fresh and brackish water areas to Plasmodium falciparum infection. Acta Tropica, 70(1): 1-7.

Savita. (2006). RAPD-PCR and polytene chromosome based genomic characterization of Anopheles subpictus Grassi (Culicidae: Diptera). M.Sc dissertation Panjab University, Chandigarh.

Simarjot. (1995). Investigations on the Genotypic Variation In Anopheles subpictus (Culiciade: Diptera). M.Sc. Dissertation, department of Zoology, Panjab University, Chandigarh.

Singh, K.R. P., Patterson, R.S., Brecque, La G.C. and Razdan, R.K. (1975). Mass rearing of Culex pipiens fatigans. Journal of Communicable Diseases, 7: 31-53.

Steiner, W.W.M, Tabachnick, W.J., Rai, K.S. and Narang, S. (1988). Recent developments in the genetics of insect disease vectors. Stipes Publ. Co. Champaign, IL, USA. pp 665.

Subbarao, S.K. (1996). Genetics of malaria vectors. Procceeding National Academy of Science, India. 66(B). Spl Issue, pp 51-76.

Subbarao, S.K., Nanda, N. and Raghavendra, K. (1999). Malariogenic stratification of India using Anopheles culicifacies siblimg species prevalence. ICMR Bulletin. 29: 75-80.
Subbarao, S.K. (1998). Anopheline species complexes in SouthEast Asia. In World Health Oarganization South-East Asia Technical Publication. No.18. pp. 81.

Subbarao, S.K. and Sharma, V.P. (1997). Anopheline species complexes and malaria control. Indian J ournal of M edical Research, 106: 164-173.

Subbarao, S.K., Nanda, N., Vasantha, K., Dua, V.K., Malhotra, M.S., Yadav, R.S. and Sharma, V.P. (1994). Population cytogenetic evidence for three sibling species in Anophel es fluvitalis (Diptera: Culicidae). Annals of Entomology American Society. 87(1): 116-121.

Subbarao, S.K., Vasantha, K. and Sharma, V.P. (1988). Cytotaxonomy of certain malaria vectors in India; in Biosystematics of Haematophagous Insects (eds) M W Service (Oxford Clarendon Press). pp 25-37.

Subbarao, S.K., Vasantha, K, Nanda, N., Nanda, N., Nagpal B.N., Vas Dev and Sharma V P. (2000). Cytotaxonomical evidence for the presence of Anopheles nivipes in India. Journal of American M osquito C ontrol Association, 16: 71-74.

Suguna, S.G. (1982). Cytological and morphological evidence for sibling species in Anopheles subpictus. Journal of Communicable Disease, 14:1-8.

Suguna, S.G., Rathinam, K.G., Rajavel, A.R. and Dhanda, V. (1994). Morphological and chromosomal descriptions of new species in the Anopheles subpictus complex. M edical Veternary Entomology, 8(1): 88-94.

Thenmozhi, V., Rajendran, R., Ayanar, K., Manavalan, R. and Tyagi, B.K. (2006). Long-term study of Japanese encephalitis virus infection in Anopheles subpictus in Cuddalore district, Tamil Nadu, South India. Tropical M edicine International H ealth, 2(3): 288-293.

Toure, Y.T., Petrarca, V., Traore, S.F., Coulibaly, A. and Maiga, H.M. (1998). The distribution and inversion polymorphism of chromosomally recognized taxa of the Anopheles gambiae complex in Mali, West Africa. Parassitologia, 40: 477-511.

Wattal, B.L. and Kalra, N.L. (1967). Regionwise pictorial keys to the female Indian Anopheles. In: Bulletin of the National Society of India for Malaria and other mosquito-borne diseases. 9(2): 85-138. 